\title{
O homem como experimento tecnológico de si
}

\section{Man as a technological experiment of himself}

\author{
Renato Rodrigues Kinouchi \\ Professor no Mestrado em Ensino, História e Filosofia da Ciência e Matemática/Universidade Federal do ABC. \\ renato.kinouchi@ufabc.edu.br
}

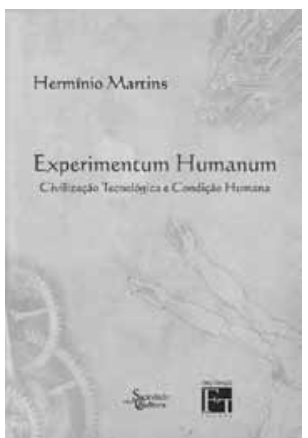

MARTINS, Hermínio. Experimentum humanum: civilização tecnológica e condição humana. Belo Horizonte: Fino Traço, 2012. 454p.

Outros há, que quando buscam as ciências, nelas buscam tudo, não só interesse, louvor, e aprovação dos homens, mas também um quase domínio deles.

(Mathias Aires, 2005, p.124)

A crença na técnica como força transformadora do mundo representa uma espécie de truísmo compartilhado por vários pensadores dos mais diversos matizes ideológicos. As consequências práticas inferidas dessa crença, entretanto, variam dramaticamente. Grosso modo, no contexto do socialismo utópico do século XIX, o avanço técnico era visto como capaz de fornecer os meios para a melhoria "contingente" das condições de vida da população, em especial da classe mais pobre e numerosa, o que por fim dissolveria as estruturas opressivas da exploração do homem pelo homem. Num registro marxista, visão semelhante era defendida, com a diferença de que nesse caso a melhoria seria "necessária", no sentido lógico da palavra, tendo em vista a própria inexorabilidade do materialismo histórico. Já para escolas de pensamento com inclinações mais totalitárias, a técnica era a mais significativa expressão da vontade de dominação do mundo, vontade que em última instância visa a si mesma como meta e como destino da humanidade. Finalmente, em tempos neoliberais, a tecnologia parece significar, no mínimo, uma melhor utilização do capital material disponível e, no limite, a própria substituição do capital material pelo capital imaterial - com o advento da economia do conhecimento - o que criaria um ciclo de enriquecimento jamais visto. Na maior parte das vezes, tais ideias são bastante sedutoras, desde que façamos vista grossa aos embaraçosos incidentes nos quais ocorre a destruição daquilo que desejávamos transformar. Mas talvez - sejamos complacentes - isso ocorra porque nenhuma delas tenha alcançado o estado de perfeição em suas aplicações, a mesma desafortunada situação das ideias promovidas pela Academia de Criadores de Lagado, satirizada por Jonathan Swift em As viagens de Gulliver, em 1726. 
Além da crença na transformação técnica da natureza, uma crença análoga, e de alcance mais espantoso, merece especial atenção, a saber, a crença na transformação técnica do homem. É fundamentalmente sobre isso que trata o livro Experimentum humanum: civilização tecnológica e condição humana, de Hermínio Martins, recentemente publicado no Brasil pela Editora Fino Traço. Composta por 11 capítulos que podem ser lidos independentemente, mas que guardam estreita relação entre si, essa obra recobre uma constelação de questões teóricas e práticas sobre a tecnologia, entre elas: as vinculações ideológicas e políticas envolvidas nos discursos sobre a tecnologia; a emergência de uma síndrome cultural representada pelo gnosticismo tecnológico, e os reflexos disso em outros fenômenos culturais tais como a arte; os riscos ambientais e sociais associados aos mais variados aparatos tecnológicos, em especial o papel da biomedicina nas guerras tecnológicas; e o processo generalizado de aceleração exponencial das mudanças ocasionadas pelas novas tecnologias, com repercussões no próprio entendimento do que seja o ser humano, dado que, para algumas dessas visões, em breve efetuaremos a passagem do humano para o pós-humano - o que significaria o derradeiro experimento-sobre-o-homem-pelo-homem, que o autor denomina Experimentum humanum.

O livro divide-se em três partes. A primeira delas apresenta questões preliminares sobre a filosofia da técnica, de tal maneira que os capítulos aí incluídos são particularmente interessantes como material de estudo para cursos voltados para tal área da filosofia. Destaco aqui o segundo capítulo, "Tecnologia, modernidade e política", no qual Martins detalha as duas grandes visões de técnica seguindo a tradicional distinção entre prometeicas e fáusticas. O que faz sua interpretação ser notável é a riqueza dos detalhes fornecidos ao longo do texto, pois essas duas imagens de técnica, longe de serem pintadas com traços marcados, são expostas por meio de minuciosas e sutis pinceladas, de tal modo que a paisagem teórica mostra-se em seus variados matizes. Nesse ínterim, cumpre assinalar a análise que Martins faz do papel ambíguo desempenhado pelos pensadores adeptos da teoria crítica, que, no entender do autor, nunca "esmiuçaram as teorias fáusticas da técnica com a mesma energia intelectual que devotaram a zurzir o positivismo" (p.58).

A segunda parte do livro versa sobre "o trágico tecnológico". Abre essa seção o instigante capítulo "Risco, incerteza e escatologia", no qual Martins investiga questões tanto teóricas como práticas das análises de risco na sociedade contemporânea. Nesse contexto, é de fundamental importância a análise que o autor faz "da insuficiência do conceito de risco" quando nos deparamos com limitações epistêmicas que impedem que logremos avaliar as consequências das aplicações das tecnologias disponíveis, de tal sorte que precisamos agregar também o conceito de incerteza, pois o risco é "essencialmente uma questão de probabilidade numérica cardinal onde as probabilidades são conhecidas ou pelo menos determináveis a partir das soluções praticadas pela indústria de seguros ... enquanto que a incerteza, pelo contrário, não pode ser avaliada probabilisticamente, pelo menos em termos de probabilidades numéricas cardinais e as opções pertinentes não podem ser sustentadas pelo recurso aos seguros" (p.181). É a partir do conceito de incerteza que Martins, mais adiante, discute o Princípio de Precaução, a ser aplicado quando não podemos avaliar o alcance e a irreversibilidade dos impactos das novas tecnologias. 
No capítulo seguinte, intitulado "Experimentos com humanos, guerra biológica e biomedicina tanatocrática", a questão do trágico tecnológico se manifesta no papel desempenhado pelas ciências da vida quando orientadas para os fins da morte. O referido capítulo pode ser considerado uma sinopse do que se denominaria "História Trágico-médica, da ciência e da medicina como tragédia, e não só como épica, como também uma reflexão filosófica sobre a experimentação científica, ou alegadamente científica, sobre humanos" (p.249). Nesse ínterim, em particular, a descrição fornecida pelo autor sobre "as justificações eugenistas" que embasavam atrocidades perpetradas em escala industrial, antes e durante a Segunda Guerra Mundial, chega a provocar calafrios. O problema é que é difícil

explicar ou compreender como uma grande elite biomédica nacional pôde participar por tantos anos desta guerra 'Santa' (como lhe chamavam os partidários japoneses da Guerra Biológica), convertendo-se, como disse, numa espécie de corpo expedicionário tanatocrático, praticando regularmente nos seus centros de trabalho 'experimentos' e vivisseções sem anestesia em seres humanos vivos ... ou investigar a inanição, a desidratação, as transfusões de sangue de animais para humanos, etc., assuntos laterais na Guerra Biológica (p.234; destaques no original).

A última parte da obra é a de natureza mais especulativa. Nela Martins discorre sobre os processos de aceleração do conhecimento científico, das tecnologias e de suas aplicações, o que em última instância culminaria em um ponto de viragem no qual o homem "poderá deixar de ser um mero homo faber ... e tornar-se finalmente o faber hominis, o Homem construtor do Homem" (p.344). É a chamada "Singularidade", ricamente discutida no capítulo "Aceleração, progresso e Experimentum humanum". Talvez o leitor considere que algumas dessas ideias sejam fantasias típicas da ficção científica e das subculturas associadas. Nesse caso, o leitor poderá se espantar com o número de autores importantes que, se não subscrevem as mesmas ideias, inclinam-se na direção de pensamentos congêneres. E, aliás, a própria realidade consumada algumas vezes parece já se haver tornado bizarramente fantástica. A título de ilustração, vale mencionar que as tecnologias reprodutivas têm engendrado a criação de um mercado de óvulos nos EUA. Nesse mercado, há uma enorme valorização de óvulos vindos de coeds de universidades prestigiosas - por exemplo, os de estudantes de Harvard chegam a ser avaliados em U\$50.000,00 -, de tal maneira que se pode traçar uma correlação entre a posição das universidades em rankings universitários e o respectivo preço dos óvulos. Em suma, quanto mais bem posicionada, maior o valor dos óvulos de suas coeds (conferir o anexo ao capítulo "Biologia e política: eugenismos de ontem e de hoje"). O que espanta não é a tecnologia empregada, nem o mercado circundante, pois isso já era visto no contexto do agrobusiness, no qual as matrizes desempenham função ligeiramente assemelhada. $\mathrm{O}$ que espanta, de fato, é a banalidade com que tais práticas se estenderam para a esfera das relações humanas. Cumpre ainda assinalar que a edição brasileira contém dois capítulos a mais do que a edição portuguesa, intitulados "Verdade, realismo e virtude" e "Dilemas da república tecnológica", os quais também merecem atenção da parte de pesquisadores da filosofia, sociologia, história da ciência e áreas correlatas.

Desejo encerrar esta breve resenha com algumas considerações acerca do autor. Hermínio Martins nasceu em Moçambique, em 1934, mas "na altura de escolher onde prosseguir os seus estudos, optou por um percurso que se distanciava do que seria mais natural - ir para 
a África do Sul - determinado a não trocar uma estrutura de dominação racial por outra idêntica" (Garcia, 2006, p.13-14). Rumou para a Inglaterra e ingressou na London School of Economics, nos tempos áureos da instituição, que contava com professores tais como Karl Popper e Ernest Gellner, este seu orientador de pós-graduação. Em 1972, publicou em inglês o primeiro ensaio de um sociólogo sobre o livro The structure of scientific revolutions, de Thomas Kuhn, apenas dois anos após o célebre volume organizado por Imre Lakatos e Alan Musgrave, Criticism and the growth of knowledge. Colaborou com inúmeros pesquisadores ao longo de sua carreira nas universidades de Leeds, Essex e Oxford, com passagens pelas universidades de Pensilvânia e Harvard. Atualmente é Emeritus Fellow no St. Antony's College da University of Oxford e investigador sênior no Instituto de Ciências Sociais da Universidade de Lisboa. Com efeito, há várias apreciações a respeito da carreira e do conjunto da obra de Hermínio Martins, dentre as quais destaco a bela entrevista feita por Helena M. Jerónimo (2011), além das recensões de José Viriato Soromenho-Marques (2012) e José Luís Garcia (2012). Não obstante, transcrevo a seguir uma passagem de João Bettencourt da Câmara (1996, p.12), na qual discorre sobre o estilo de Hermínio Martins: "Os textos de Hermínio Martins são por norma densos, compactos, estanques e escritos com uma elegância e luxo vocabulares que faz as delícias do leitor especializado, mas, também, por vezes, o desespero do neófito e do tradutor. São exemplos de uma economia de estilo que permite escrever em trinta ou cinquenta páginas o que outros escreveriam num livro de duzentas ou trezentas, e sem grandes folgas". De fato, os ensaios contidos no livro Experimentum humanum são densos, invejavelmente eruditos e, ademais, completamente atuais. A despeito de tais características, são particularmente prazerosos pelo fato de o autor saber, como poucos, como fazer com que a "última flor do Lácio" desprenda seus aromas mais sofisticados. Levando-se em consideração que a edição brasileira, publicada pela Fino Traço, contém 454 páginas, o leitor pode estar certo de que o livro é diversão garantida, e por bastante tempo.

\section{REFERÊNCIAS}

AIRES, Mathias.

Reflexões sobre a vaidade dos homens: carta sobre a fortuna. Lisboa: Imprensa Nacional; Casa da Moeda. 2005.

CÂMARA, João Bettencourt da.

Hermínio Martins ou o Sociologus Rex. In: Martins, Hermínio. Hegel, Texas e outros ensaios de teoria social. Lisboa: Edições Século XXI. p.7-15. 1996.

GARCIA, José Luís.

A plenitude tecnológica em questão. Hermínio Martins e o Experimentum humanum: civilização tecnológica e condição humana. Análise Social, Lisboa, v.47, n.2, p. 483-489. 2012.
GARCIA, José Luís.

Razão, tempo e tecnologia em Hermínio Martins. In: Cabral, Manuel Villaverde; Garcia, José Luís; Jerónimo, Helena Mateus. Razão, tempo e tecnologia: estudos em homenagem a Hermínio Martins. Lisboa: Imprensa de Ciências Sociais. p.14-47. 2006.

JERÓNIMO, Helena Mateus.

Entrevista a Hermínio Martins. Análise Social, Lisboa, v.46, n.3, p. 460-483. 2011.

SOROMENHO-MARQUES, Viriato.

Hermínio Martins, pensador da crise contemporânea. Análise Social, Lisboa, v.47, n.2, p.479-482. 2012. 